\title{
Benefits Conditional on Work and the Nordic Model*
}

\author{
Ann-Sofie Kolm ${ }^{\dagger}$ and Mirco Tonin ${ }^{\ddagger}$ \\ May 12, 2014
}

\begin{abstract}
Welfare benefits in the Nordic countries are often tied to employment. We argue that this is one of the factors behind the success of the Nordic model, where a comprehensive welfare state is associated with high employment. In a general equilibrium setting, the underlining mechanism works through wage moderation and job creation. The benefits make it more important to hold a job, thus lower wages will be accepted, and more jobs created. Moreover, we show that the incentive to acquire higher education improves, further boosting employment in the long run. These positive effects help counteracting the negative impact of taxation.

Through numerical simulations, we show how this mechanism can contribute to explain the better labor market performance and more equitable income distribution of Nordic countries compared to Continental European ones.
\end{abstract}

JEL codes: H24, J21, J24

Keywords: Nordic model, in-work benefits, wage adjustment, unemployment, education, skill formation, earnings

*We want to thank Torben Andersen, Martin Flodén, Richard Freeman, Mathias Herzing, Eddie Lazear, Ethienne Lehman, Bruno van Linden, and participants at the Conference on the Economics of the Nordic Model. We also would like to thank the Editor and three anonymous referees for very thoughtful reviews of the paper.

${ }^{\dagger}$ Department of Economics, Stockholm University, S-106 91 Stockholm, Ph. +468 163547. Fax +46 8 161425, E-mail address: ann-sofie.kolm@ne.su.se

${ }_{\ddagger}^{\ddagger}$ Economics Division, University of Southampton, UK; Economics Department, UniCredit \& Universities Fellow, Central European University, Budapest; IZA, Bonn; and CESIfo, Munich. Email address: m.tonin@soton.ac.uk 


\section{Introduction}

A prominent feature of the so-called Nordic model is a comprehensive welfare state financed by taxes on labor. In fact, the public sector in many of the Nordic countries is responsible for the distribution and allocation of resources amounting to more than half of their country's GDP (Eurostat, 2012). With an emphasis on redistributional transfers and service provision financed by taxes on labor, a concern with the model is, of course, that it induces weak incentives to work. In a more long term perspective, such a system may also reduce incentives to acquire skills, with a negative impact on future productivity and labor market outcomes. However, external observers are often surprised that the Nordic countries manage to combine low unemployment and high labor force participation with high taxes, generous welfare arrangements, and a more equitable income distribution. So, how is this possible?

One answer to this question is that many of the welfare arrangements in the Nordic countries are closely tied to market work. The generosity of many welfare benefits is, in general, related to earnings. In addition, eligibility to a number of benefits and social services is conditional on employment. One obvious example is the recently introduced earned income tax credit, which by definition is exclusively targeted to employed workers. In the case of Sweden, for instance, the credit applies for all individuals with income from work and has no phase-out region (Edmark et al., 2012). Other examples are subsidized childcare and paid parental leave schemes. These are very important policies in the Nordic countries. Comparing, as in Rogerson (2007), four Nordic and four Continental European countries, it is indeed evident (top panel of Figure 1) that public expenditures on childcare as percent of GDP are substantially larger in the Nordic countries compared to Continental Europe. Only in France subsidies are fairly generous, however they can be reaped irrespective of how the secondary earner, usually the mother, spends her time. In Sweden, on the other hand, the childcare subsidy is contingent on that both parents work. ${ }^{1}$ It is also worth noticing that, at 0.9 percent of GDP, expenditures on childcare subsidies in Sweden are about three times as large as the US expenditures on the EITC. ${ }^{2}$ The importance of childcare subsidies in explaining labor market performance in Sweden and the other Nordic countries is also stressed by Rosen (1997) and Rogerson (2007). The Nordic countries also spend substantially more resources on paid parental leave than countries in Continental Europe (bottom panel in Figure 1). ${ }^{3}$ The leave schemes are constructed so to provide generous payments to employed workers on leave, while nonemployed workers get no or very low payments. In addition, a lengthy period of time in a job is needed to become entitled to the benefit. The idea behind these policies is that, by increasing the net returns from working, they increase the supply of labor.

\footnotetext{
${ }^{1}$ From 2001, the program in Sweden was expanded to allow the children of parents who were unemployed the right to attend childcare for fifteen hours per week, in order to enable job search. See Kolm and Lazear (2010) for a description of the childcare subsidies in Sweden. In Denmark unemployed workers are entitled to childcare subsidies conditional on full time search and participation in active labor market programs. For a short description of the French system see http://www.cleiss.fr/docs/regimes/regimefrance/an4.html.

${ }^{2}$ By transferring about $\$ 45$ billion to around 25 million low income families in the US, the Earned Income Tax Credit (EITC) is one of the most important programs for stimulating employment and fighting poverty in the US. The spending on EITC corresponds to about 0.3 percent of GDP. There are very strong similarities in the construction of the employment contingent childcare subsidies in Sweden and the EITC in the US, although an important difference, of course, is that the childcare subsidies are in kind.

${ }^{3}$ For a review of the parental leave policies in different countries see Moss (2012).
} 
Figure 1: Spending on Childcare and Parental Leave

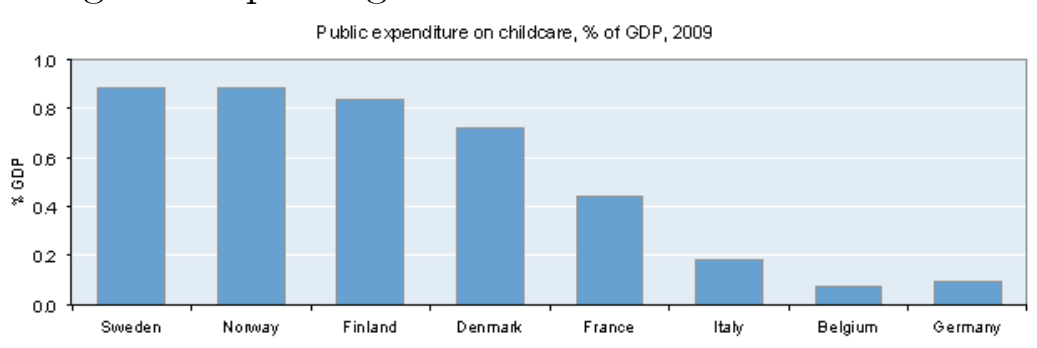

Source: Sacial Expenditure dat abæe 2013; 0ECD Education dat abæe.

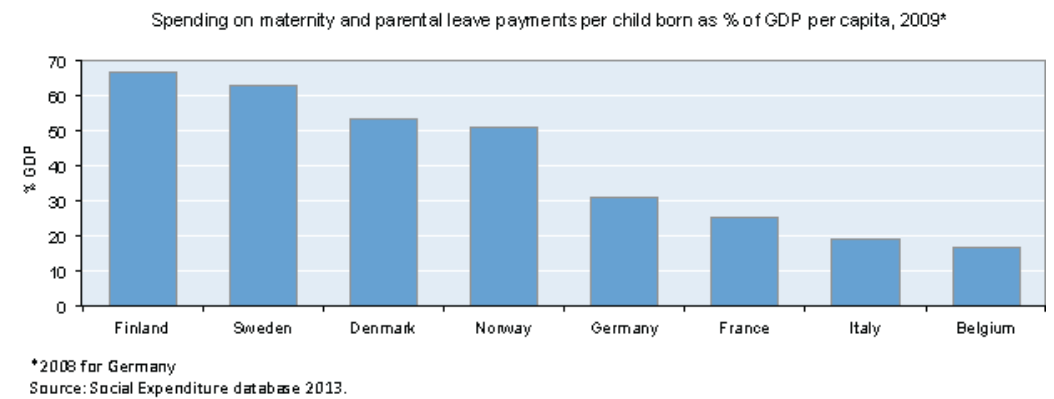

The observation that the Nordic countries have sustained high economic activity because benefits are closely tied to market work is not new. In fact this was noted as a contributing factor to the high participation rate observed in Sweden when a group of NBER economists studied the Swedish welfare state in the mid 1990s (see Freeman et al., 1997). In that volume, Björklund and Freeman (1997) indeed write "[w]hat is impressive is that so much of the Swedish welfare system is work based" (page 50). Also Andersen (2010) writes that the "social safety net in the Scandinavian countries is at the same time both generous and employment conditioned".

The starting point for this paper is that entitlement to many of the benefits available in the Nordic countries is conditional on employment. As discussed above, this tends to increase the gains from working, which encourages labor supply. However, we argue that this is not the end of the story. To investigate the full impact of welfare state arrangements of this type, one needs to account for the general equilibrium effects. This is particularly relevant because many benefits have been available to the whole population for a long period of time. Clearly, to investigate the effects of these benefits on employment, which is an equilibrium outcome, both supply-side and demand-side factors must be included in the analysis. Moreover, besides considering the equilibrium outcome for the existing workforce, it is important to account for the impact of these benefits on incentives to acquire skills. The equilibrium composition of the workforce in terms of educational attainment is a crucial variable for the sustainability of the Nordic model, both in terms of its growth potential and international competitiveness (Andersen, 2008) and in terms of the political support for the welfare state (Hassler et al., 2003).

To carry out such an analysis, we develop a version of the Diamond-MortensenPissarides search-and-matching model. Labor force participation is endogenously determined, and individuals differ in their ability to acquire education, with the choice of educational attainment based on a cost-benefit analysis. In particular, we focus on the choice between proceeding to higher, i.e. tertiary, education or not. The aim is to investigate the implications of benefits that are conditional on work on unemployment and labor force participation, accounting for their long term impact on educational attainments. 
We show that, when disregarding the impact on the government budget constraint, the effect of benefits available only to employed workers is to moderate wages, reduce unemployment rates, and increase labor force participation and employment. Workers are willing to accept lower wages when benefits are conditional on work. Lower wages, in turn, increase job creation and lower the unemployment rate, thus also boosting participation. Moreover, and perhaps surprisingly, we find that the incentives to proceed to higher education are strengthened. There are two reasons for this. First, a work contingent benefit increases the expected income relatively more for highly educated workers, and, second, as education only pays off on the labor market, increased labor force participation will induce increased educational attainments among former non-participating high ability workers. Thus, total employment increases for three sets of reasons. First, benefits reduce the unemployment rate for workers at all educational levels. Second, as more workers choose to acquire higher education, the expected unemployment spells become shorter. Third, as labor force participation increases with the benefits, a larger share of the population will be employed. We show, through numerical simulations, that general equilibrium effects can play a substantial role, in particular for unemployment.

We also find that taking into account the impact of benefits on the government budget constraint actually reinforces wage moderation and, as such, does not overrule the results that benefits increase job creation and reduce unemployment rates. However, it weakens the incentives to acquire higher education and participate in the labor force, thus inducing a counteracting effect on educational attainment and labor force participation.

In a numerical example, we compare the labor market and educational outcomes of an environment in which proportional taxation is used to finance benefits conditional on employment to an environment with the same tax rate but unconditional benefits. This is meant to capture in a very stylized way the difference between Nordic and Continental European countries. What we show is that conditionality makes a big difference for both educational and labor market outcomes, thus potentially representing an important element in the success of the Nordic model. We also show that conditional benefits generate a more equitable income distribution compared to unconditional ones.

Considering the previous literature, there are a number of studies that have tried to explain why the Nordic countries have performed so well despite high taxes and generous welfare arrangements. As mentioned, some of these studies have emphasized the importance of the fact that benefits are tied to market work for the successful outcome in terms of employment and participation (see Aronsson and Walker, 1997, Andersen, 2008, 2010). A related view is provided by Rogerson (2007). He argues that the governments' spending pattern in the Scandinavian countries, compared to other high tax Continental European countries, can potentially explain the large number of aggregate work hours observed in these countries. He shows, holding tax rates constant, that it matters if the revenue is spent on disability payments which may only be received when an individual does not work, or on subsidies for childcare. Our study also finds that how the government choose to spend tax revenues matters for labor market performance, although for a different reason. Unlike Rogerson (2007) we investigate this question in a search-andmatching equilibrium framework with involuntary unemployment. An important part of our results arises via general equilibrium effects working through wage moderation.

This study is also related to the large literature on earned income tax credits (EITCs) as such a tax credit is available only to workers with income from work. ${ }^{4}$ This literature,

\footnotetext{
${ }^{4}$ Theoretical papers, usually based on standard neoclassical labor supply models, investigate the effects of the EITC on work hours (Eissa and Hoynes, 2006) or on the extensive margin (Saez, 2002).
} 
however, has only recently been concerned with the implications of EITC policies when wages respond to the policy. Rothstein (2010) investigates the impact of the US EITC in a model featuring a perfectly competitive labor market, accounting for the behavioral responses in labor force participation and work hours. He finds that the increased labor supply following the EITC leads to lower wages in equilibrium. This, in turn, dampens the equilibrium impact on labor supply. Kolm and Tonin (2011) contrast the impact of an EITC when wages are fixed and when equilibrium wage adjustments are accounted for using a search and matching model. They also find that wages fall with the tax credit in equilibrium, but this actually amplifies the positive impact of the EITC on search intensity, participation, and employment.

Research on the impact of an EITC on education is rather limited. While not looking at education, the paper by Heckman, Lochner and Cossa (2003) is related as it studies the impact of wage subsidies on on-the-job skill formation, distinguishing between a model with learning-by-doing and a model with training on the job. They show that on-the-job training models predict that wage subsidies reduce skill formation, while learning-bydoing models predict the opposite. A recent paper by Malul and Luski (2009) contrasts the effects of a minimum wage and an EITC on incentives to acquire human capital. They find that a minimum wage policy increases the professional level, as individuals need to "defend" themselves against unemployment, while the EITC reduces the incentive to invest in human capital because of the implicit tax created by the "phase out" of the EITC subsidy. In contrast to the existing literature, our paper highlights the impact of in-work benefits on educational attainment going through the general equilibrium effects, in particular through the impact on wages and job creation.

The rest of the paper is organized as follows. Section 2 presents a simple model of the labor market and analyses the implications of benefits conditional on work on labor market outcomes and educational choice. Section 3 provides numerical simulations. The last section concludes.

\section{The Model}

This section develops a simple model of a non-clearing labor market with unemployment as an equilibrium outcome. More specifically, we use a version of the DiamondMortensen-Pissarides search-and-matching model (see Pissarides, 2000, and Mortensen and Pissarides, 1994). ${ }^{5}$

The policy in consideration is benefits conditional on work. As mentioned, a crucial feature of many welfare policies in the Nordic countries is that benefits, in different ways, are conditional on employment. ${ }^{6}$ In the model, we let one parameter, denoted $I W B$,

For empirical papers, see Eissa and Liebman, 1996, Meyer and Rosenbaum, 2001, Chetty, Friedman and Saez, 2013.

${ }^{5}$ The Nordic model is, in addition to its comprehensive welfare state and high taxes, associated with strong unions. This suggests that a union-firm wage bargaining model is relevant. The results derived in this paper are qualitatively the same using a model where unions bargain with firms over wages (see Appendix).

${ }^{6}$ Also benefits that are accessible when not employed, like unemployment benefits (UB), are strongly tied to market work because the generosity, as well as the entitlement, is based on earnings and work in previous periods. Although generous UB tends to increase wages and increase unemployment rates, and thus for these variables work as the mirror image to employment contingent benefits, the fact that entitlement and generosity are tied to work increases the returns from working. See Fredriksson and Holmlund (2001) for a general equilibrium approach of UB and their optimality. 
capture in-work benefits.

The population is heterogenous in terms of ability to acquire education. Ability, $a$, is for simplicity distributed according to a standard uniform distribution, and individuals decide on the educational level they wish to pursue based on their ability. For simplicity the educational choice is between acquiring higher education, such as a college education, or not.

Also labor force participation is endogenously determined. The population is heterogenous in terms of how leisure when out of the labor force, $l$, is valued, which for simplicity is also distributed according to a standard uniform distribution and, for analytical tractability, is assumed to be independent from the distribution of ability.

\subsection{Matching}

We assume that unemployed workers with a higher level of education will only search for jobs targeted to workers with higher education, and vice versa for workers with a lower level of education. ${ }^{7}$ The matching process of vacancies and unemployed job searchers within an educational category is captured by a concave and constant-returns-to-scale matching function of the Cobb-Douglas form, $X_{j}=v_{j}^{1-\eta} u_{j}^{\eta}$, where $X_{j}$ is the matching rate, $v_{j}$ is the vacancy rate, and $u_{j}$ is the unemployment rate. Index $j=L, H$ refers to the educational categories: low educated $(\mathrm{L})$, and high educated $(\mathrm{H})$. The matching, unemployment, and vacancy rates are defined relative to the labor force of the educational category.

The transition rate into employment for a worker with a given level of education is $X_{j} / u_{j}=\lambda\left(\theta_{j}\right)=\theta_{j}^{1-\eta}$, where $\theta_{j}=v_{j} / u_{j}$ denotes labor market tightness. Firms fill vacancies at the rate $X_{j} / v_{j}=q\left(\theta_{j}\right)=\theta_{j}^{-\eta}$. Higher labor market tightness, $\theta_{j}$, increases workers' probability of finding a job, but reduces the probability of a firm finding a worker, i.e., $\lambda^{\prime}\left(\theta_{j}\right)>0$ and $q^{\prime}\left(\theta_{j}\right)<0$, where $\eta=-\frac{q^{\prime}\left(\theta_{j}\right)}{q\left(\theta_{j}\right)} \theta_{j}$ is the elasticity of the expected duration of a vacancy with respect to tightness.

\section{$2.2 \quad$ Workers and Firms}

Let $E_{j}$ and $U_{j}$ denote the expected present values of employment and unemployment of workers with a given educational level. The flow value functions for a worker with education $j$ are:

$$
\begin{aligned}
r E_{j i} & =w_{j i}(1-t)+I W B-s\left(E_{j i}-U_{j}\right)-I(j) c(a), j=L, H, \\
r U_{j}(a) & =\lambda\left(\theta_{j}\right)\left(E_{j}-U_{j}\right)-I(j) c(a), j=L, H,
\end{aligned}
$$

where $w_{j i}$ is the wage agreed upon in the worker-firm pair $i, t$ is the proportional income tax rate, and $r$ and $s$ denote the exogenous discount and separation rates. The term $I W B$ denotes the in-work benefit which, by definition, is a benefit accessible only when employed. The cost of attaining higher education is $c(a)$, where $c^{\prime}(a)<0$ captures that workers with higher ability face lower costs of acquiring higher education. We model the

\footnotetext{
${ }^{7}$ This assumption could, however, be relaxed along the lines of Mortensen and Pissarides (1999), by allowing workers to look for jobs where they are overqualified, and thus allowing firms to employ workers with an educational level above what is required for the job. In equilibrium, however, workers would not find it optimal to search for jobs where they are overqualified, and firms would not find it optimal to hire overqualified workers, leading to the endogenous outcome of a segmented equilibrium as assumed here.
} 
educational cost as a cost to acquire and maintain skill. This is a simplifying assumption and is not important for the results. ${ }^{8}$ The indicator function $I(j), j=L, H$, takes the value zero for low educated workers and the value one for high educated workers, hence $I(L)=0$ and $I(H)=1$.

There is a large number of small firms searching for workers with a particular education. Each firm employs one worker only. Let $J_{j}$ and $V_{j}$ denote the expected present values of an occupied and vacant job for a given level of educational requirements. The flow value functions of a specific occupied job and a vacant job can then be written as:

$$
\begin{gathered}
r J_{j i}=y_{j}-w_{j i}-s\left(J_{j i}-V_{j}\right), j=L, H, \\
r V_{j}=-k+q\left(\theta_{j}\right)\left(J_{j}-V_{j}\right), j=L, H,
\end{gathered}
$$

where $k$ denotes vacancy costs and $y_{j}$ denotes productivity. Firms that search for highly educated workers adopt a more advanced technology, which implies that the productivity will be higher in those firms once production starts. For the same reason firms that search for less educated workers adopt a less advanced technology, with the implication that productivity is lower once production gets started. Thus, we have $y_{H}>y_{L}$. Firms will enter freely into the market by posting vacancies as long as it is profitable to do so, inducing in equilibrium $V_{j}=0, j=L, H$.

\subsection{Wage Formation and Tightness}

Matching frictions create quasi-rents, and these rents are assumed to be shared according to Nash bargaining, where the worker has bargaining power $\beta$. The wage satisfies $w_{j i}=$ $\arg \max \left(E_{j i}-U_{j}\right)^{\beta}\left(J_{j i}-V_{j}\right)^{1-\beta}$. In symmetric equilibrium with free entry, i.e. with $V_{j}=0$, the bargaining solution satisfies $\beta J_{j}=(1-\beta)\left(E_{j}-U_{j}\right)$. This condition and the flow value functions in (1)-(4) yield the wage rule:

$$
w_{j}=\beta\left(y_{j}+k \theta_{j}\right)-(1-\beta) \frac{I W B}{1-t}, j=L, H .
$$

From $V_{j}=0$, and equations (3)-(4), tightness in equilibrium is determined by:

$$
\frac{k(r+s)}{q\left(\theta_{j}\right)}=(1-\beta)\left(y_{j}+\frac{I W B}{1-t}\right)-\beta k \theta_{j}, j=L, H,
$$

where the equilibrium wage follows recursively from (5) once tightness is pinned down by (6).

In equilibrium, the flow into unemployment equals the flow out of unemployment for each category of workers. ${ }^{9}$ The equilibrium unemployment rate facing workers with a given level of education is:

$$
u_{j}=\frac{s}{s+\theta_{j}^{1-\eta}}, j=L, H,
$$

which depends positively on the separation rate and negatively on tightness.

\footnotetext{
${ }^{8}$ The assumption enables us to use a model without having workers continuously being born and dying. Such a model would, however, generate the same qualitative expressions.

${ }^{9}$ Thus, $s\left(1-u_{L}\right) L F P_{L}=\lambda\left(\theta_{L}\right) u_{L} L F P_{L}$, and $s\left(1-u_{H}\right) L F P_{H}=\lambda\left(\theta_{H}\right) u_{H} L F P_{H}$, where $L F P_{j}$, $j=L, H$, denotes the labor force for each educational category. The size of the labor force for each educational level is endogenous and will be determined in the next section. However, as the unemployment rates are independent of the size of the labor force it is of no importance how we note them here.
} 
To highlight the various mechanisms behind the impact of work contingent benefits, we first consider the impact of an $I W B$ on labor market performance holding the tax rate $t$ constant. The results are summarized in the following proposition:

Proposition 1 An increase in IWB will reduce wages, increase tightness and takehome pay, and reduce the unemployment rate for workers in all educational categories.

Proof. See appendix.

The in-work benefit, which by definition is conditional on work, simply increases the attractiveness of having a job. When holding a job becomes more attractive, wage demands will be moderated. This makes it more profitable for firms to open vacancies, which in turn, induces tightness to increase and the equilibrium rate of unemployment to fall. Although the $I W B$ restrains wage demands, take-home pay increases. As wage restraints stimulate job creation which, in turn, reduces the expected unemployment spells, more workers will transit from unemployment into jobs, thus leading to higher expected life time earnings. These results are also shown in Kolm and Tonin (2011), where we consider the impact of an EITC.

\subsection{Education, Labor Force Participation, and Employment}

We assume that educational attainment only gives a payoff to workers in jobs. ${ }^{10}$ Thus, only workers that will participate in the labor market will consider whether they should acquire higher education or not. As workers enter the labor market into the state of unemployment, they compare the value of unemployment at different educational attainments when making their decision. The condition determining the ability level of the marginal worker is:

$$
r U_{L}=r U_{H}(\hat{a}),
$$

where $\hat{a}$ is the ability level of the worker which is indifferent between acquiring higher education or not. By use of (1) and (2), the condition can be rewritten as

$$
c(\hat{a})=\left(1-\phi\left(\theta_{H}\right)\right)\left[w_{H}(1-t)+I W B\right]-\left(1-\phi\left(\theta_{L}\right)\right)\left[w_{L}(1-t)+I W B\right],
$$

where the right hand side captures the gain of education in terms of a higher expected income, as $1-\phi\left(\theta_{j}\right)$ can be interpreted as the expected time in employment. ${ }^{11}$ This gain needs to exceed the individual cost of acquiring education, in order for the individual to attain additional education. Thus, workers with low ability, i.e., if $a \leq \hat{a}$, will not find it worthwhile to proceed to higher education, whereas high ability workers, i.e., $a>\hat{a}$, will find it worthwhile to do so. An $I W B$ will affect the expected income of workers both directly and through its impact on wages and the expected time in employment.

We can rewrite condition (8) further, by using (1) and (2), together with the first order conditions for wages, and the equations in (4) under the assumption of free entry.

\footnotetext{
${ }^{10}$ Education could, of course, also have some consumption value. Accounting for this would not change the results and one could consider the cost of education as modelled here to be net of any benefit enjoyed regardless of labor market status.

${ }^{11}$ The weight, $1-\phi\left(\theta_{j}\right)=\frac{\lambda\left(\theta_{j}\right)}{r+s+\lambda\left(\theta_{j}\right)}$, reduces down to the employment rate, $1-u_{j}$, when the discount rate approaches zero.
} 
This yields:

$$
c(\hat{a})=\frac{\beta k(1-t)}{(1-\beta)}\left(\theta_{H}-\theta_{L}\right),
$$

where the right hand side of equation (10) is equivalent to the expected income gain of getting a college education, as can be seen from (9). In order to guarantee that at least some workers acquire additional education, expected income must increase with education. Ignoring the $I W B$, this can be shown to hold formally by use of the equations in (6) where $\theta_{H}>\theta_{L}$ if $y_{H}>y_{L}$. The $I W B$ may affect the individual incentives to acquire education by affecting tightness, and thus the expected income, in a different way at the two levels of education. This is the particular issue up for investigation here.

By assuming that the cost function fulfills $\lim _{a \rightarrow 1} c(a)=0$ and $\lim _{a \rightarrow 0} c(a)=+\infty$, we can focus on the non-trivial case where at least some workers find it worthwhile to acquire higher education while others don't. Although equation (10) is used to pin down who in the labor force will proceed to higher education and who will not, to get an expression for the number of workers in the population with higher education, we also need to know who will participate in the labor market.

A worker enters the labor force into the state of unemployment by becoming available to the labor market. It will be worthwhile to enter the labor market if the returns of entering exceed the returns from not entering. Let $N$ denote the expected present value of non-participation. The flow value of not participating in the labor force is given by the per period real value of leisure, $l$, which differs across workers.

The flow value function for non-participation, $r N=l$, is then added to the flow value functions for employment and unemployment in (1)-(2). The assumption is that it is not important if the worker has a higher education or not for the worker's evaluation of leisure when out of the labor force, and thus subindex $j$ is absent. The function determining the valuation of leisure which makes the worker indifferent between participating and not participating in the labor market is given by the following continuous function:

$$
\begin{aligned}
& \hat{l}=r U_{L} \text { if } a \leq \hat{a}, \\
& \hat{l}=r U_{H}(a) \text { if } a>\hat{a} .
\end{aligned}
$$

This function can be rewritten by use of the flow value functions in (2) in symmetric equilibrium, the Nash bargaining solutions, $\beta J_{j}=(1-\beta)\left(E_{j}-U_{j}\right)$, and the free entry condition, $V_{j}=0, j=L, H$, together with (4), $\operatorname{as}^{12}$ :

$$
\begin{aligned}
& \hat{l}=\frac{\theta_{L} \beta k(1-t)}{(1-\beta)} \text { if } a \leq \bar{a}, \\
& \hat{l}=\frac{\theta_{H} \beta k(1-t)}{(1-\beta)}-c(a) \text { if } a>\hat{a} .
\end{aligned}
$$

A worker that would not proceed to higher education when participating, i.e. a worker with $a \leq \hat{a}$, will not find it worthwhile to participate in the labor market if his or her valuation of leisure exceeds $\hat{l}=\frac{\theta_{L} \beta k(1-t)}{(1-\beta)}$. Workers with very high ability, on the other hand, may choose to participate in the labor market even if they have a high valuation of leisure. This follows as their pay-off on the labor market is very high accounting for that they fairly effortlessly can acquire higher education and reap a higher expected income.

\footnotetext{
${ }^{12}$ As we use the standard uniform distribution for $\hat{l}$, the value of the function should not exceed unity. For simplicity we assume that this is not binding, that is, this threshold level is lower than unity. In what follows we will assume to be in an interior solution.
} 
Figure 2: Labor force participation and educational attainment

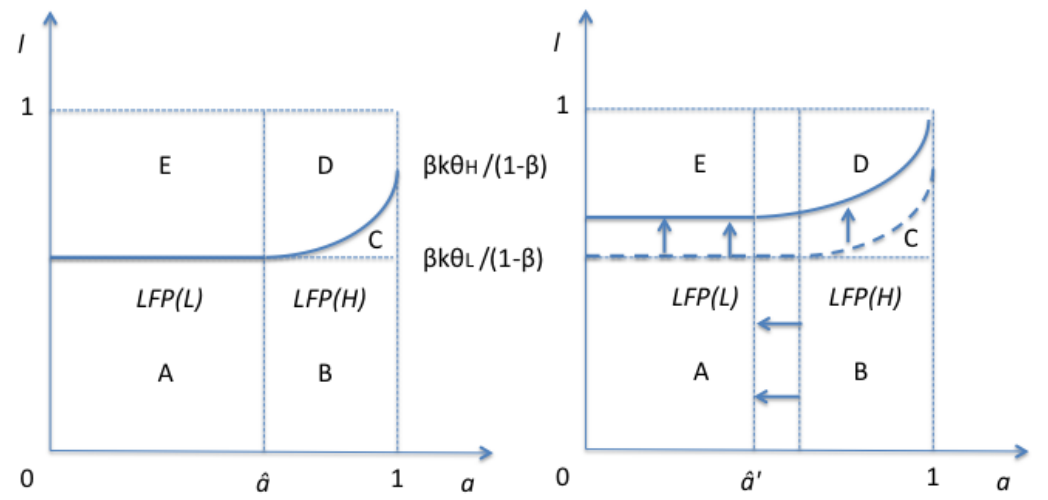

Figure 2 illustrates the choice of participation and education in the population. Areas $A, B$ and $C$ in the left panel give the stock of workers participating in the labor market. Areas $B$ and $C$ give the stock of workers that will acquire higher education. Area $D$ captures workers that would, in case of participation, acquire higher education. However, as they will not participate in the labor market due to their high valuation of leisure, they will not acquire higher education as education is costly and only gives a payoff when working. This implies that the labor force participation rate is larger for workers with high ability. More specifically, the labor force participation rate is given by the area $(B+C) /(B+C+D)$ for workers with high ability, i.e. $a>\hat{a}$, and by the area $A /(A+E)$ for workers with lower ability, i.e. $a \leq \hat{a}$. The labor force participation rate for workers with low education is $A /(A+D+E)$, while by assumption workers acquire high education only if they intend to participate in the labor market.

It is then straightforward to derive labor force participation, $L F P$, the stock of educated workers, Edu, and total employment, Emp, in the economy as:

$$
\begin{aligned}
L F P & =\frac{\hat{a} \beta k \theta_{L}(1-t)}{(1-\beta)}+\frac{(1-\hat{a}) \beta k \theta_{H}(1-t)}{(1-\beta)}-\int_{\hat{a}}^{1} c(a) d a \\
E d u & =\frac{(1-\hat{a}) \beta k \theta_{H}(1-t)}{(1-\beta)}-\int_{\bar{a}}^{1} c(a) d a, \\
E m p & =\left(1-u_{L}\right) \frac{\hat{a} \beta k \theta_{L}(1-t)}{(1-\beta)}+\left(1-u_{H}\right)\left[\frac{(1-\hat{a}) \beta k \theta_{H}(1-t)}{(1-\beta)}-\int_{\hat{a}}^{1} c(a) d a\right]
\end{aligned}
$$

The effect of in-work benefits on labor force participation, education, and employment, for a given tax rate $t$, are summarized in the following proposition.

Proposition 2 An increase in IWB will increase labor force participation, the stock of workers with higher education, and aggregate employment. 
Proof. See appendix.

Labor force participation increases with work contingent benefits both because the expected unemployment spells becomes shorter and because the take-home pay for workers at all educational levels increases. Thus an $I W B$ increases the expected income of participation. Moreover, benefits conditional on work increase the incentives for workers to acquire higher education. There are two reasons for this. First, an $I W B$ increases the expected income relatively more for highly educated workers, inducing $\hat{a}$ to fall. As the likelihood of being in a job is higher for highly educated, a higher IWB pays off relatively more for the highly educated, thus increasing the incentives for education. This direct effect is further reinforced by the fact that an $I W B$ increases the likelihood of being in a job relatively more for highly educated workers. ${ }^{13}$ Second, as an $I W B$ increases the return to participation, some workers with very high ability will find it worthwhile to leave their state of non-participation and join the labor force. As these workers have a very high ability, they will also find it worthwhile to acquire higher education.

The right panel in Figure 2 illustrates how labor force participation and the stock of workers with higher education are affected by an $I W B$. What can be noticed is that there is a leftward shift in the line denoting the ability level where workers are indifferent between acquiring higher education or not. This corresponds to the first of the two reasons described above for the increase in higher education. The second reason is represented by the upward shift in the line denoting, for each ability level, the value of leisure leaving a worker indifferent between participating or not in the labor market.

Aggregate employment increases for three sets of reasons. First, employment increases because benefits conditional on work increase job creation which reduces the unemployment rate for all educational categories. Second, as benefits improve the incentives to acquire education, employment increases as the expected unemployment spells are shorter among highly educated workers. Third, as labor force participation increases, employment increases because some of the workers entering the labor market will become employed.

So far we have disregarded the impact of an increase in benefits on the tax rate. To account for that, we now consider the government budget constraint:

$$
t * W a g e B i l l=I W B * E m p,
$$

where the total wage bill in the economy is given by:

$$
\begin{aligned}
\text { WageBill }= & w_{L}\left(1-u_{L}\right) \frac{\hat{a} \beta k \theta_{L}(1-t)}{(1-\beta)}+ \\
& +w_{H}\left(1-u_{H}\right)\left[\frac{(1-\hat{a}) \beta k \theta_{H}(1-t)}{(1-\beta)}-\int_{\hat{a}}^{1} c(\hat{a}) d a\right] .
\end{aligned}
$$

We can then show the following:

\footnotetext{
${ }^{13}$ Labor market opportunities increase for all workers. However, because there is relatively more competition for workers with high education, an additionally vacancy has a smaller negative externality on other firms when posted to high, rather than to low, educated workers. Thus, $\theta_{H}$ will increase by more than $\theta_{L}$, and will thereby increase the expected time in employment, and thus the expected income, relatively more for highly educated workers. Note also that the adjustments in tightness implies that wage moderation will be relatively smaller for highly educated workers, implying a larger increase in take-home pay following an increase in $I W B$ for highly educated workers.
} 
Proposition 3 An increase in IWB financed by proportional taxes on wages will reduce wages, increase tightness, and reduce the unemployment rate for workers at all educational levels provided a higher tax rate implies higher fiscal revenues.

Proof. See appendix.

An $I W B$ financed by proportional taxation on wages will again reduce wages and the unemployment rate for workers at all educational levels. There is an ambiguous effect on the incentives to proceed to higher education. As the expected income increases relatively more for highly educated workers, more workers tend to proceed to higher education with an $I W B$. However, the fact that taxation is more harmful to high income earners directly reduces the payoff from education, which induces less workers to acquire education. Taxes will also have a direct negative effect on take-home pay, labor force participation, and employment. Next, we turn to numerical simulations to illustrate these effects.

\section{A Numerical Example}

In this section we calibrate the model and simulate the impact of an in-work benefit on the main variables of interest. To illustrate the different mechanisms through which an $I W B$ works, we first disregard the impact on the tax rate and contrast the effects of the benefit with flexible vs. fixed wages. Then, we take into account the government budget constraint and compare a labor market where revenues are used to finance an $I W B$, as modeled in section 2, to a labor market where revenues are used to finance a lump-sum transfer that is not conditional on work.

Following Rogerson (2007), we base this numerical example on a comparison between four Nordic countries (Denmark, Finland, Norway, and Sweden) and four countries in Continental Europe (Belgium, France, Germany, and Italy). According to data from Eurostat, average general government expenditures over the period 1993-2012 have been $51 \%$ of GDP for the four countries in Continental Europe and $53 \%$ for the four Nordic countries, thus indicating that the "weight" of government in the economy is similar in the two groups. ${ }^{14}$ Also, what Eurostat defines as "implicit tax rate on labor"15 has been very similar in the two groups of countries. The average during the period 1995-2011 (for which data are available) has been $41 \%$ in Continental Europe and $40 \%$ in the Nordic countries.

In terms of educational attainment of the population, the Nordic countries perform better than the four countries in Continental Europe, with a larger share of the population aged 25-64 with tertiary degrees, $32 \%$ vs. $23 \%$, or with secondary degrees, $48 \%$ vs. $43 \%{ }^{16}$ Nordic countries have generally been performing better also in labor market terms. The average unemployment rate over the period 1996-2012 for workers in the age

\footnotetext{
${ }^{14}$ Average general government revenues over the period 1993-2012 were $47 \%$ of GDP in Continental Europe and $56 \%$ of GDP in the Nordic countries.

${ }^{15}$ This is based on the separation of taxes into three economic functions (consumption, labor, and capital), and is computed as the ratio of total tax revenues of the category labor to a proxy of the potential tax base defined using the production and income accounts of the national accounts (Eurostat, 2010).

${ }^{16}$ Data come from Eurostat and are unweighted averages for the period 1996-2012 (for Germany 1998 is missing). Tertiary education refers to first and second stage of tertiary education (ISCED levels 5 and 6). Secondary education refers to upper secondary and post-secondary non-tertiary education (ISCED levels 3 and 4). The remaining category, primary education, refers to pre-primary, primary and lower secondary education (ISCED levels 0-2).
} 
group 25-64 has been $7.7 \%$ in Continental Europe and $5.1 \%$ in the Nordic countries. In both groups of countries, there is a large difference depending on educational level, with the unemployment rate for those with less than tertiary education $(8.9 \%$ in Continental Europe and $6.0 \%$ in the Nordic countries) almost double than for those with tertiary education (4.6\% in Continental Europe and 3.5\% in the Nordic countries). In terms of labor force participation, the overall figure for Continental Europe is $74 \%$ and for the Nordic countries $83 \%$, with, again, a substantial difference across educational levels, as labor force participation is $70 \%$ in Continental Europe and $79 \%$ in the Nordic countries for those with less than tertiary education, while the corresponding figures for those with tertiary education are $87 \%$ and $90 \%$. Finally, Nordic countries are also characterized by a more equitable income distribution. The average Gini index of equivalized disposable income over the period 2005-2012 is 0.25, while the average for Continental Europe is 0.29 .

Thus, all in all, while Nordic countries are rather similar to countries in Continental Europe in terms of taxation on labor, they perform better in terms of labor market outcomes and educational attainment, and have a more equitable income distribution. In what follows, we will calibrate and simulate the model developed in the previous section to show how big a difference the mechanism highlighted in this paper can make. More specifically, we will compare an economy where tax revenues are spent to provide benefits conditional on work to an economy where benefits are not conditional on work, with the caveat that, given the simplicity of the model, we consider these calculations as illustrative, without aiming to provide specific guidance in terms of the empirical impact of having benefits conditioned on work.

\subsection{Calibration}

The month is the basic time unit and the real interest rate $r$ is 0.0025 . To ensure that the labor force participation rate for low educated workers is always less than 1, productivity for low educated workers, $y_{L}$, is fixed at 0.6. ${ }^{17}$ Petrongolo and Pissarides (2001) in their literature survey consider $[0.5,0.7]$ to be the range of plausible values for $\eta$, and we fix it at 0.5. There are not many estimates of $\beta$, but the conventional value used in the literature is 0.5 . To capture the strong market power in the wage bargains of workers in the Nordic countries, as well as in Continental Europe, we fix $\beta$ at $0.6{ }^{18}$ Parameters $k, s$, and $y_{H}$ are set to replicate an average duration of unemployment for the low educated of 6 months and an unemployment rate of $9 \%$ for low educated, and $5 \%$ for high educated in absence of an in-work benefit. The two unemployment rates are thus similar to the ones prevailing in the countries of Continental Europe. For analytical convenience, we assume that the cost of acquiring higher education is given by

$$
c(a)=2 \delta(1-a) .
$$

The share of people with high education in the population, Edu, is given by (12). The parameter $\delta$ is set to replicate a distribution of educational attainment in absence of an in-work benefit with $E d u=0.4$, so that, once benefits are introduced, the proportion of people acquiring higher education resembles the share of population with tertiary degrees. The table below summarizes the parametrization ${ }^{19}$.

\footnotetext{
${ }^{17}$ In the simulations we constrain the participation rate for each skill level to never exceed unity.

${ }^{18}$ However, fixing $\beta$ at 0.5 gives similar results.

${ }^{19}$ Further details about the calibration are provided in the Appendix.
} 


\begin{tabular}{cccccccc}
\hline$y_{L}$ & $y_{H}$ & $\beta$ & $k$ & $r$ & $s$ & $\eta$ & $\delta$ \\
\hline \hline 0.6 & 1.96 & 0.6 & 12.1 & 0.0025 & 0.016 & 0.5 & 1.442 \\
\hline
\end{tabular}

\subsection{Flexible vs. fixed wages}

Figure 3 plots the main variables of interest as a function of an in-work benefit going from 0 to 0.3 , equivalent to half the productivity of people with low education. To disentangle the different effects of benefits contingent on work, we report both the effects of in-work benefits with flexible wages (continuous line) and with fixed wages (dotted line). In both cases, the tax rate $t$ is kept fixed.

Looking first at the case with flexible wages, we can see that, as expected, tightness increases and the share of the population with higher education increases, going from $40 \%$ of the population with no benefits to almost $44 \%$ when benefits are at 0.3 . As underlined in section 2.4, education increases both because of higher labor force participation by high ability agents with high value of leisure and because of changes in the schooling cutoff, so that more workers with intermediate ability find it worthwhile to acquire higher education. To decompose the contributions of these two channels, we also report the educational level in the population keeping the cutoff $\hat{a}$ constant. It is then evident that, with this calibration, the increase in education is mostly due to higher labor force participation by high ability agents with high value of leisure.

Looking at unemployment rates, they fall both for the highly educated (from $5 \%$ to $4.6 \%$ ) and for people with low education (from $9 \%$ to $7.4 \%$ ). The overall unemployment rate is also influenced by the composition of the workforce, and it decreases from $6.7 \%$ to $6 \%$. Also as expected, the labor force participation rate increases and, as a result of a higher participation, lower unemployment rates, and more educational acquirements, the total employment rate in the population increases.

Although the share of population acquiring higher education increases, the share of highly educated in the labor force declines as there is a significant increase in participation for those with low education. We also look at the share of those with high ability, i.e. with ability above $\hat{a}$, deciding to pursue higher education. This share increases because the in-work benefit makes it worthwhile for high ability workers with a high value of leisure to acquire higher education and participate in the market. ${ }^{20}$

Beside the obvious difference in terms of tightness, the main difference between flexible and fixed wages emerges with respect to unemployment. Unemployment rates for each of the two education categories are constant without wage adjustments, and the overall unemployment rate is actually slightly increasing instead of decreasing as with flexible wages. The total unemployment rate increases in the fixed wage case because of the significant increase in labor force participation for the low educated, who have a high unemployment rate. General equilibrium effects add to the positive direct effect of inwork benefits on employment (going from $80.6 \%$ with fixed wage to $81.8 \%$ with flexible wages when $I W B=0.3$ ) and participation, even if quantitatively this difference is more modest. In addition, the general equilibrium effects slightly moderate the increase in educational attainment in the population compared to the fixed wage case.

\footnotetext{
${ }^{20}$ Of course, the threshold $\hat{a}$ defining higher ability people also changes with the level of benefits.
} 

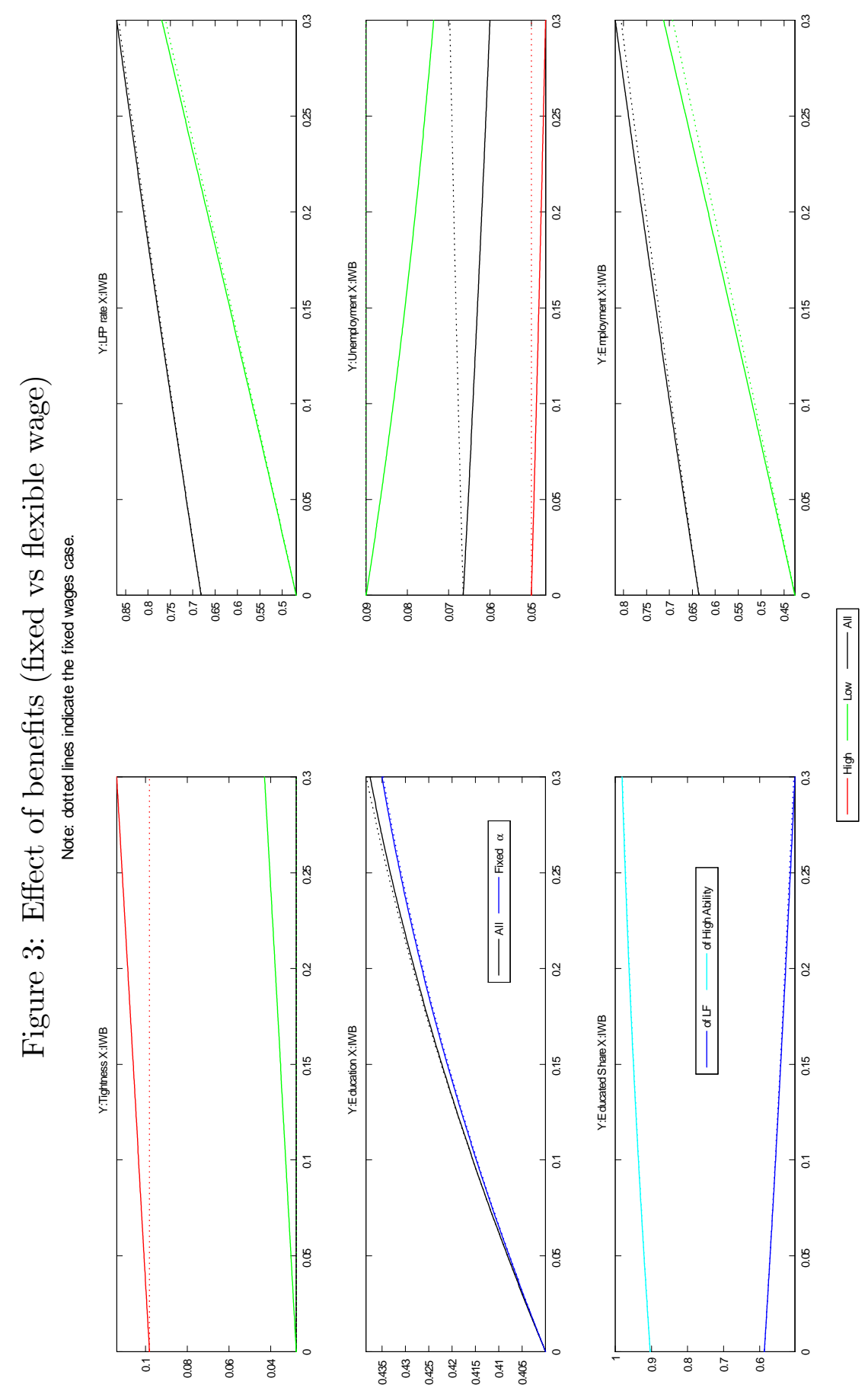


\subsection{Conditional vs. unconditional benefits}

We now compare labor market outcomes and educational attainment depending on whether benefits are conditional on work (Figure 4, continuous line) or not (Figure 4, dotted line), taking also into account the effect on taxes. As mentioned, the first case is meant to capture the Nordic countries, while the second case is more similar to countries in Continental Europe. To facilitate comparisons with the previous figure, the $\mathrm{x}$-axis in Figure 4 measures $I W B$. For the case of conditional benefits, $I W B=0.30$ corresponds to a tax rate of $25.5 \%$, while for $I W B=0.15$ the tax rate is $11.4 \%$. For unconditional benefits, we then plot the outcome corresponding to the same tax rate, so that the comparison is between economies with the same tax rate using revenues to finance $I W B$ (continuous line) or unconditional benefits (dotted line).

As highlighted in section 2, when accounting for the effect of benefits on the government budget constraint, higher benefits reduce the incentives to acquire higher education, as their financing implies higher taxes. This follows simply because the tax rates hits the high income earners, i.e. the highly educated, significantly stronger. However, while the share of the population with higher education falls from $40 \%$ to $31.2 \%$ when benefits are conditional on work, it falls by an additional 5 percentage points, to $26.2 \%$ with unconditional benefit. Considering that there is a 9 percentage points difference between Nordic and Continental countries in terms of the share of population attaining higher education, this implies that the mechanism proposed in this paper can potentially account for a large portion of the difference.

Comparing the "overall" and "fixed $\hat{a}$ " curves we can see that with conditional transfers the increase in the schooling cutoff is the main driver of the decline, with the lower participation by high ability agents also making a significant impact. For unconditional transfers the relative contribution of the two channels is reversed. The intuition behind these results is that both taxes and benefits conditional on work have a very strong impact on the participation decision for high ability workers with a high value of leisure. Taxes reduce the incentives to participate for this group whereas conditional benefits increase the incentives to participate, thus significantly reducing the negative effect of taxation on participation, while this is not the case for unconditional transfers.

When taxes are used to finance an unconditional transfer, there is no effect on tightness and unemployment rates. However, because of the adverse impact of taxation on the incentives to acquire higher education, the overall unemployment rate increases with taxation because of a composition effect, going from $6.7 \%$ to $7 \%$ as taxes increase. When benefits are conditional on work, the unemployment rate falls for both educational levels, going from $5 \%$ to $4.6 \%$ and from $9 \%$ to $7 \%$ for the two educational groups, and from $6.7 \%$ to $6 \%$ overall. The difference is very large regarding labor force participation, increasing from $68 \%$ to $75 \%$ for conditional transfers, while declining to just above $50 \%$ in the unconditional case. The combined effect on participation and unemployment results in a large difference in terms of employment as well. Finally, due to the combined effects on education and labor force participation, the educated share of the labor force declines more with conditional transfers.

Again, this simple calibration suggests that the mechanism proposed in this paper can contribute to explain the 2.6 percentage points difference in terms of the average unemployment rate and the 9 percentage points difference in participation rates between Nordic and Continental European countries. 


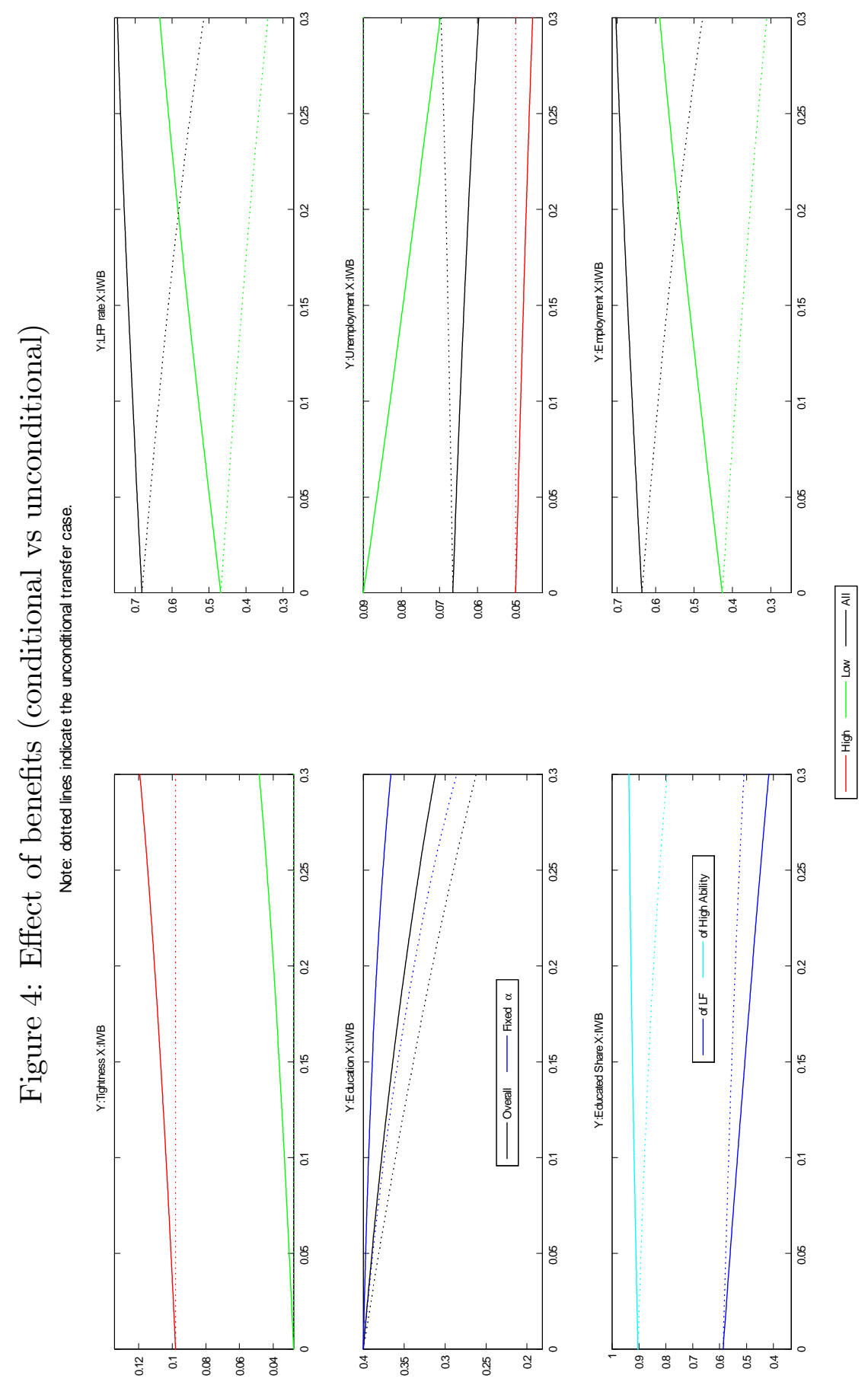


As mentioned at the beginning of this section, the Nordic model is also characterized by a rather equitable income distribution. The model developed in this paper is clearly not ideal to assess distributional issues, as, for instance, we only have three income levels (high wage, low wage, not working). It can however be informative to compare benefits conditional on work and lump-sum transfers also along this dimension. Given the calibration, the level of the Gini index ${ }^{21}$ without benefits stands at 0.51 . Introducing proportional taxes to finance an $I W B=0.15$ or an $I W B=0.30$ reduces the index to 0.49 and 0.45 respectively. Applying the corresponding tax rate to finance instead an unconditional transfer reduces the Gini index much less, to 0.51 and 0.48. The levels of the index clearly do not resemble what observed in either the Nordic or Continental countries, but it is interesting to notice that, perhaps contrary to intuition, conditional transfers may generate a more equitable distribution than unconditional ones, at least as measured by the Gini index. Despite the fact that the gap in income between those not working and those working is larger with conditional transfers, the more positive labor market outcomes associated with in-work benefits implies that a much lower share of the population draw a low income, thus making the overall income distribution more equitable.

\section{Conclusions}

As mentioned in the introduction, the Nordic countries are characterized by a comprehensive welfare state financed through taxes and social security contribution. High social spending financed through high taxes characterizes many other countries, especially in continental Europe. What this paper has emphasized is that one feature of the Nordic model, namely the fact that many of the welfare arrangements are strongly tied to work, makes a difference. In particular, we have underlined how benefits structured in such a way induce job creation and lower the unemployment rate through their wage moderating effect. Moreover, they do provide incentives to pursue further education, and increase labor force participation and employment. We have shown how the labor market outcome is very different if, for a given tax rate, spending is directed towards programs that are not conditional on work. The difference would be even larger, of course, with programs conditional on not working.

We have also emphasized one crucial aspect behind the long-term sustainability of the Nordic model, namely its effect on incentives to pursue higher education. As Andersen (2008) noticed in his discussion on the prospects and challenges of the Nordic model, "a compressed wage structure and high taxation have a negative effect on the return to education". This paper shows how benefits conditional on work mitigate this negative incentive and may contribute, together with other policies like the public financing of education, to maintain the educational attainment in the Nordic countries at high levels.

Although we show that benefits conditional on work may be an important factor behind the success of the Nordic model, this paper leaves a lot for future research. For example, childcare subsidies are not just benefits conditional on work. They also shift childcare activities from the private sphere into the public sphere. A thorough investigation of their impact on labor market outcomes should also take into account this aspect. In addition, this paper does not compare the welfare implications of conditional and

\footnotetext{
${ }^{21}$ The Gini index is calculated for a population of 1000 individuals split into three income categories reflecting the shares arising from the model.
} 
unconditional benefits, nor does it analyze the optimal level of benefits. Such analysis would require, among other things, risk averse individuals. The numerical simulations, however, suggest that benefits conditional on work may help in squaring the concern for both efficiency and equity.

\section{References}

[1] Andersen T. M., 2008, The Scandinavian Model - Prospects and Challenges, International Tax and Public Finance 15, p. 45-66.

[2] Andersen T. M., 2010, Why do Scandinavians Work?, CESifo Working Paper No. 3068.

[3] Aronsson T., and Walker, J., 1997, The effects of Sweden's welfare state on labor supply incentives. In: Freeman, R., B. Swedenborg, and R. Topel (Eds.), The Welfare State in Transition: Reforming the Swedish Model, University of Chicago Press.

[4] Björklund, A., and Freeman, R. B., 1997. Generating Equality and Eliminating Poverty, the Swedish Way. In: Freeman, R., B. Swedenborg, and R. Topel (Eds.), The Welfare State in Transition: Reforming the Swedish Model, University of Chicago Press.

[5] Chetty, R., Friedman, J., and Saez, E., 2013. Using Differences in Knowledge Across Neighborhoods to Uncover the Impacts of the EITC on Earnings, American Economic Review 103, 2683-2721.

[6] Edmark, K., Liang, C. Y., Eva, M., and Selin, H. (2012). Evaluation of the Swedish earned income tax credit. Uppsala University, Department of Economics WP 2012:3.

[7] Eissa, N., and Hoynes, H., 2006. Behavioral responses to taxes; Lessons from the EITC and Labour Supply. Tax Policy and the Economy 20, 73-110.

[8] Eissa, N., and Liebman, J., 1996. Labor Supply Responses to the Earned Income Tax Credit. Quarterly Journal of Economics 111, 605-37.

[9] Eurostat, 2010. Taxation trends in the European Union, Luxembourg: Publications Office of the European Union

[10] Eurostat, 2012. Statistics in focus N. 27.

[11] Freeman, R., B. Swedenborg, and R. Topel (Eds.), 1997, The Welfare State in Transition: Reforming the Swedish Model, University of Chicago Press.

[12] Fredriksson, P., and Holmlund, B., 2001. Optimal Unemployment Insurance in Search Equilibrium. Journal of Labor Economics 19(2), 370-99.

[13] Hassler, J., Storesletten, K., and Zilibotti, A. 2003. The Survival of the Welfare State. The American Economic Review, 93(1), 87-112.

[14] Heckman, J., Lochner, L., and Cossa, R. 2003. Learning-by-doing vs. On-the-job Training: Using Variation Induced by the EITC to Distinguish Between Models of Skill Formation. In: Phelps, E. S. (Ed.). Designing inclusion: tools to raise low-end pay and employment in private enterprise. Cambridge university press. 
[15] Kolm, A-S., and Lazear, E., 2010, Policies Affecting Work Patterns and Labor Income for Women. In: R. Freeman, B. Swedenborg, and R. Topel (Eds.), Reforming the Welfare State - Recovery and Beyond in Sweden, The University of Chicago Press, 57-82.

[16] Kolm, A-S., and Tonin, M., 2011, In-Work Benefits and Unemployment. International Tax and Public Finance, 18 (1), 74-92.

[17] Malul, M., and Luski, I. 2009. The Optimal Policy Combination of the Minimum Wage and the Earned Income Tax Credit. The BE Journal of Economic Analysis \& Policy, 9(1).

[18] Meyer, B., and Rosenbaum, D., 2001. Welfare, the earned income tax credit and the labour supply of single mothers. Quarterly Journal of Economics 116, 1063-1114.

[19] Mortensen, D., and Pissarides, C., 1999. Unemployment Responses to 'Skill-Biased' Technology Shocks: The Role of Labour Market Policy. The Economic Journal 109, 242-265.

[20] Mortensen, D., and Pissarides, C., 1994. Job Creation and Job Destruction in the Theory of Unemployment. Review of Economic Studies 61, 397-415.

[21] Moss, P., 2012, International Review of Leave Policies and Related Research 2012, Annual report, International Network on Leave Policies and Research.

[22] OECD, 2011, Education at a Glance 2011: OECD Indicators, OECD Publishing.

[23] Petrongolo B., and Pissarides, C., 2001. Looking into the Black Box: A Survey of the Matching Function. Journal of Economic Litarature 39, 397-415.

[24] Pissarides, C., 2000. Equilibrium unemployment theory, MIT Press, Boston, MA.

[25] Rogerson, R., 2007. Taxation and Market Work: is Scandinavia an Outlier? Economic Theory, 32(1), 59-85.

[26] Rosen, S.,1997. Public employment, taxes, and the welfare state in Sweden. In: Freeman, R., B. Swedenborg, and R. Topel (Eds.), The Welfare State in Transition: Reforming the Swedish Model, University of Chicago Press.

[27] Rothstein, J., 2010, Is the EITC as Good as an NIT? Conditional Cash Transfers and Tax Incidence, American Economic Journal: Economic Policy 2 (1), 177-208.

[28] Saez, E., 2002. Optimal Income Transfer Programs: Intensive Versus Extensive Labor Supply Responses. Quarterly Journal of Economics 117, 1039-1073. 


\section{Appendix}

\section{A1 Proofs of propositions}

Proposition 1. Differentiation of the equations in (6) yields: $\frac{d \theta_{j}}{d I W B}=\frac{(1-\beta)}{(1-t)} \frac{1}{\left[k(r+s) \eta \theta^{\eta-1}+\beta k\right]}>$ 0 . Then differentiation of (7) yields $\frac{d u_{j}}{d I W B}=-\frac{(1-\eta) s \theta_{j}^{-\eta}}{\left(s+\theta_{j}^{1-\eta}\right)^{2}} \frac{d \theta_{j}}{d I W B}<0$. Differentiation of (5) making use of the expressions for $\frac{d \theta_{j}}{d I W B}$ yields $\frac{d w_{j}}{d I W B}=-\frac{(1-\beta)}{(1-t)} \frac{k(r+s) \eta \theta^{\eta-1}}{\beta k+k(r+s) \eta \theta^{\eta-1}}<0$. The impact of an $I W B$ on the take-home pay is: $\frac{\left.d\left(w_{j}(1-t)\right)+I W B_{j}\right)}{d I W B}=1+(1-t) \frac{d w_{j}}{d I W B}=$ $\beta\left[1+(1-t) k \frac{d \theta_{j}}{d I W B}\right] \in(0,1)$.

Propositions 2. The impact of an $I W B$ on labor force participation, the stock of education, and employment is considered through differentiation of (10)-(13) and using the previous proposition. Differentiation of (11) yields $\frac{d L F P}{d I W B}=\frac{\hat{a} \beta k(1-t)}{(1-\beta)} \frac{d \theta_{L}}{d I W B}+$ $\frac{(1-\hat{a}) \beta k(1-t)}{(1-\beta)} \frac{d \theta_{H}}{d I W B}>0$ as changes in $\hat{a}$ will have no impact on $L F P$. Differentiation of (10) using the expression for $\frac{d \theta_{j}}{d I W B}$ and the facts that $c^{\prime}(\cdot)<0$ and $\theta_{H}>\theta_{L}$ yields $\frac{d \hat{a}}{d I W B}=\frac{\beta k(1-\beta)}{c^{\prime}(\hat{a})(1-\beta)}\left[\left[k(r+s) \eta \theta_{H}^{-(1-\eta)}+\beta k\right]^{-1}-\left[k(r+s) \eta \theta_{L}^{-(1-\eta)}+\beta k\right]^{-1}\right]<0$. Differentiation of (12) and (13) yield $\frac{d E d u}{d I W B}=-\frac{d \hat{a}}{d I W B} \frac{\beta k \theta_{L}(1-t)}{(1-\beta)}+\frac{(1-\hat{a}) \beta k(1-t)}{(1-\beta)} \frac{d \theta_{H}}{d I W B}>0$ and $\frac{d E m p}{d I W B}=-\frac{d u_{L}}{d I W B} \frac{d \theta_{L}}{d I W B}-\frac{d u_{H}}{d I W B}\left[\frac{(1-\hat{a}) \beta k \theta_{H}}{(1-\beta)}-\int_{\hat{a}}^{1} c(a) d a\right]+\left(1-u_{L}\right) \frac{\hat{a} \beta k(1-t)}{(1-\beta)} \frac{d \theta_{L}}{d I W B}+(1-$ $\left.u_{H}\right) \frac{(1-\hat{a}) \beta k(1-t)}{(1-\beta)} \frac{d \theta_{H}}{d I W B}-\frac{d \hat{a}}{d I W B} \frac{\beta k(1-t)\left(\theta_{H}\left(1-u_{H}\right)-\theta_{L}\left(1-u_{L}\right)\right)}{(1-\beta)}>0$, using that $\frac{(1-\hat{a}) \beta k \theta_{H}}{(1-\beta)}-\int_{\hat{a}}^{1} c(a) d a>$ 0 as that is the labor force participation of highly educated workers, and $\theta_{H}>\theta_{L}, u_{H}<u_{L}$ and that $\frac{d \hat{a}}{d I W B}<0, \frac{d \theta_{H}}{d I W B}>0$.

Propositions 3. Differentiation of (6) yields $\frac{d \theta_{j}}{d I W B}=\frac{(1-\beta)}{(1-t)^{2}}\left[\frac{\left[1-t+I W B \frac{d t}{d I W B}\right]}{\left[k(r+s) \eta \theta^{\eta-1}+\beta k\right.}\right]>0$ if $\frac{d t}{d I W B}>0$. From (7) it then follows that $\frac{d u_{j}}{d I W B}=-\frac{(1-\eta) s \theta_{j}^{-\eta}}{\left(s+\theta_{j}^{1-\eta}\right)^{2}} \frac{d \theta_{j}}{d I W B}<0$ if $\frac{d t}{d I W B}>0$. Also, differentiation of (5) and by use of the expression for $\frac{d \theta_{j}}{d I W B}$, we have $\frac{d w_{j}}{d I W B}=$ $-\frac{(1-\beta)}{(1-t)^{2}} \frac{k(r+s) \eta \theta^{\eta-1}}{\beta k+k(r+s) \eta \theta^{\eta-1}}\left[1-t+I W B \frac{d t}{d I W B}\right]<0$ if $\frac{d t}{d I W B}>0$. It is clear that $\frac{d t}{d I W B}>0$ from the direct effect in (14) (ignoring the indirect effects working through the tax bases of employment and the wage bill). Accounting for the dynamic effects implies that the government revenue can both increase and fall with higher taxes. By assuming $\frac{d t}{d I W B}>0$, we assume that the dynamic effects working through the tax bases are not dominating the direct effects.

\section{A2 Calibration - Derivation}

The parameters $k$ and $s$ are set to replicate, in absence of an $I W B$, an unemployment rate for the low educated of $\bar{u}_{L}$ and an average duration of unemployment for the low educated of $d_{u L}$ months. Given (7) and the fact that $d_{u L}=\frac{1}{\lambda\left(\theta_{L}\right)}=\frac{1}{\theta_{L}^{1-\eta}}$, we get

$$
s=\frac{\bar{u}_{L}}{d_{u L}\left(1-\bar{u}_{L}\right)}
$$


and

$$
\theta_{L}=\left(s \frac{1-\bar{u}_{L}}{\bar{u}_{L}}\right)^{\frac{1}{1-\eta}} .
$$

Then, using (6) and the fact that $q\left(\theta_{j}\right)=\theta_{j}^{-\eta}$, we can get the following expression for $k$

$$
k=\frac{(1-\beta) y_{L}}{(r+s) \theta_{L}^{\eta}+\beta \theta_{L}} .
$$

Given $\bar{u}_{H}$ and using the expression for $\theta_{H}$ corresponding to (19), it is possible to derive the implied $\theta_{H}$. Using (6) again and the value for $\theta_{H}$ derived above, it is then possible to calculate $y_{H}$

$$
y_{H}=\frac{k(r+s) \theta_{H}^{\eta}+\beta k \theta_{H}}{1-\beta} .
$$

Finally, using (17) in conjunction with (10) and the fact that the share of people with higher education, $E d u$, is given by (12), we get, $\delta=\frac{(\beta k)^{2}\left(\theta_{H}-\theta_{L}\right)\left(\theta_{H}+\theta_{L}\right)}{4(1-\beta)^{2} E d u}$.

\section{A3 Simulations with Financing}

Using equations (6), (10), and (14) for a given level of $I W B$, we have four unknowns $\left(\theta_{H}, \theta_{L}, \hat{a}, t\right)$ solving the system of equations

$$
\begin{gathered}
k(r+s) \theta_{L}^{\eta}-(1-\beta)\left(y_{L}+\frac{I W B}{1-t}\right)+\beta k \theta_{L}=0 \\
k(r+s) \theta_{H}^{\eta}-(1-\beta)\left(y_{H}+\frac{I W B}{1-t}\right)+\beta k \theta_{H}=0 \\
1-\hat{a}-\frac{\beta k(1-t)}{2 \delta(1-\beta)}\left(\theta_{H}-\theta_{L}\right)=0 \\
(1-\hat{a})\left(\frac{\theta_{H}^{1-\eta}}{s+\theta_{H}^{1-\eta}}\right)\left[\beta\left(y_{H}+k \theta_{H}\right)-(1-\beta) \frac{I W B}{1-t}-\frac{I W B}{t}\right]+ \\
+\hat{a}\left(\frac{\theta_{L}^{1-\eta}}{s+\theta_{L}^{1-\eta}}\right)\left[\beta\left(y_{L}+k \theta_{L}\right)-(1-\beta) \frac{I W B}{1-t}-\frac{I W B}{t}\right]=0
\end{gathered}
$$

We can use equation (22) to solve for $I W B$ as a function of $\theta_{H}$ and $t$,

$$
I W B=\frac{k(r+s) \theta_{H}^{\eta}+\beta k \theta_{H}-y_{H}(1-\beta)}{(1-\beta)}(1-t) .
$$

We can then use this expression to replace $I W B$ in $(23)$ to get

$$
(1-\beta)\left(y_{H}-y_{L}\right)-k(r+s)\left(\theta_{H}^{\eta}-\theta_{L}^{\eta}\right)-\beta k\left(\theta_{H}-\theta_{L}\right)=0 .
$$

We can use expression (24) to replace $\hat{a}$ in (25), expression (26) to replace $I W B$ in the first line of (25) and a similar expression using (23) instead of (22) to replace $I W B$ in the second line of (25). This gives the following equation

$$
\begin{gathered}
\left(\frac{\theta_{L}^{1-\eta}}{s+\theta_{L}^{1-\eta}}\right) \theta_{L}\left[2 \delta(1-\beta)-\beta k(1-t)\left(\theta_{H}-\theta_{L}\right)\right] * \\
*\left[(1-\beta) y_{L}-(1-\beta t) k(r+s) \theta_{L}^{\eta}-(1-t) \beta k \theta_{L}\right]+ \\
\quad+\left(\frac{\theta_{H}^{1-\eta}}{s+\theta_{H}^{1-\eta}}\right) \frac{1}{2} \beta k(1-t)\left(\theta_{H}-\theta_{L}\right)\left(\theta_{H}+\theta_{L}\right) * \\
*\left[(1-\beta) y_{H}-(1-\beta t) k(r+s) \theta_{H}^{\eta}-(1-t) \beta k \theta_{H}\right]=0
\end{gathered}
$$


Using (27) and (28), we have a system of two equations in two unknowns $\left(\theta_{H}, \theta_{L}\right)$ that we solve numerically. We can then get $\hat{a}$ from (24) and $I W B$ from (26).

\section{A4 Alternative Models of Wage Setting}

The impact of $I W B$ on labor market outcomes studied in this paper is robust to different models of wage setting behavior. In an efficiency wage model, for instance, $I W B$ provide firms with an instrument to discipline workers. Thus, the firm need not pay workers as high wages in order to prevent them from shirking, since the threat of loosing the benefit when fired will do the job. Also, the same result would materialize in a static or dynamic union-firm wage bargaining model of the Right-to-Manage type, or in a Monopoly union model. The effect of an $I W B$ in a static Right-to-Manage model is illustrated below.

\section{Union-Firm Wage Bargaining}

We assume that unions, representing workers at the firm level, bargain with firms over the wage. However, once the wage is set, the firms will decide on how many workers to hire. The problem is solved through backward induction. Thus, at the second stage, firms decide the number of workers to hire, $N$, so as to maximize their profit, $\Pi$, taking the wage, $w$, as predetermined. Firms then solve $\operatorname{Max}_{N} \Pi=A N^{\alpha}-w N$, where, for simplicity, the production technology is captured by a Cobb-Douglas function, and the individual and sector specific indexes are dropped until needed. We assume that workers and firms are separated into a low skilled sector and a high skilled sector. Productivity differences across the two sectors are captured by the productivity parameter $A>0$, where $A_{H}>A_{L}$. The firm's demand for labor is then given by:

$$
N=\left(\frac{w}{A \alpha}\right)^{-\frac{1}{1-\alpha}}
$$

Wages are set through decentralized union-firm Nash bargaining. The union's utilitarian objective function is captured by $\Omega=N[w+I W B]+(\bar{N}-N) \bar{w}$, where $\bar{N}$ is the number of union members, and $\bar{w}$ captures the expected income when unemployed. The union face a trade-off in that a higher wage improves the well-being of their employed members, but a higher wage will, at the same time, render more members unemployed, which reduces the well-being of those members. $\bar{N} \bar{w}$ captures the union fallback position. This leaves $N[w+I W B-\bar{w}]$ as the union "rent" contribution in the bargain. Note that unions representing educated workers also need to account for the cost of education. However, as the cost of education remains also when the bargaining breaks apart, the costs will not enter into the union's contribution to the Nash product. As the firm makes no profit in case the bargain breaks apart, the Nash product is given by

$$
\Lambda=[N(w+I W B-\bar{w})]^{\lambda}\left[A N^{\alpha}-w N\right]^{1-\lambda},
$$

where $\lambda$ is the relative bargaining strength of the union compared to the firm, $\lambda \in(0,1]$. The Nash product is maximized by choosing $w$, accounting for that $N=N(w)$ through (31). From the first order condition, the following wage setting curve can be derived:

$$
w=\frac{\alpha+\lambda(1-\alpha)}{\alpha}[\bar{w}-I W B]
$$


where it is clear that also in a union-firm wage bargaining model wage demands will fall due to in-work benefits. The intuition is analogous to the one found in the basic matching model. As an in-work benefit increases the value of having a job, the union wage demand is restrained because they want more of their member to be in jobs.

To investigate the long run impact of $I W B$ on labor market outcomes, however, we need to extend the model by allowing for free entry of firms and educational choice. In addition, we need to assume that the expected income when unemployed, $\bar{w}$, accounts for the possibility of becoming employed again. Thus, we make the standard assumption of letting $\bar{w}=(1-u)(w+I W B)+u B$, where $u$ is the unemployment rate and $B$ is unemployment benefits. ${ }^{22}$ By substituting this expression for $\bar{w}$ into (32), we get the following long run wage setting curve:

$$
u=\frac{\lambda(1-\alpha)}{\alpha+\lambda(1-\alpha)} \frac{1}{\left[1-\frac{(B-I W B)}{w}\right]} .
$$

Let's now consider the demand side. As in the matching model, we assume that firms will enter into the market as long as they make positive profits. Thus, the following free entry condition holds, $A N^{\alpha}-w N-K=0$, where $K$ represents the fixed cost of entry. This can be rewritten, using the firm labor demand function in (31), as:

$$
A^{\frac{1}{1-\alpha}} w^{-\frac{\alpha}{1-\alpha}}\left[\alpha^{\frac{\alpha}{1-\alpha}}-\alpha^{\frac{1}{1-\alpha}}\right]-K=0 .
$$

From (34) it is clear that the demand side alone determines the wage in equilibrium, and that the equilibrium wage is not affected by the $I W B$. As the wage is unaffected in equilibrium, so will the number of workers hired by each firm, $N$, (residually determined by (31)), although there are, as will be shown below, more firms operating on the market. The wage moderation materializes on the supply side, as the wage setting curve shifts down, reducing the unemployment rate $^{23}$ :

$$
\frac{d u}{d I W B}=-\frac{\lambda(1-\alpha)}{\alpha+\lambda(1-\alpha)} \frac{1}{w\left[1-\frac{(B-I W B)}{w}\right]^{2}}<0 .
$$

Thus also when we have a union-firm wage bargaining set up will an $I W B$ reduce the unemployment rate.

The condition saying that the total number of workers hired by firms is the same as the total number of workers in the labor force that have a job, $(1-u) L F=k N$, where $k$ is the number of firms, and $L F$ denotes the size of the labor force, determines the number of firms. Rewritten we have:

$$
k=\frac{(1-u) L F}{N} .
$$

As the $I W B$ increases, $u$ falls, and the number of firms on the market, $k$, increases for a given size of the labor force, $L F$.

\footnotetext{
${ }^{22}$ None of the comparative static results derived depends on that unemployment benefits are positive.

${ }^{23}$ This was also the case in the matching model as shown in proposition 1 . In the matching model, however, the demand side represented by the job creation curve was negatively sloped in $w$ and $(1-u)$ space, making part of the shift in the wage setting curve materialized in lower wages and part of it in a lower unemployment rates. In this set up, the lower wage following from the reduced wage demands will, in equilibrium, be counteracted by more firms entering the market pushing the wage up to its equilibrium level again.
} 
As in the matching model when workers differ in their ability to acquire education, we can derive the ability level of the marginal worker getting education, $\breve{a}$, by comparing the expected income of a low educated worker with that of a high educated worker. Accounting for the cost of education, this yields:

$$
\left(1-u_{L}\right)\left(w_{L}+I W B\right)+u_{L} B=\left(1-u_{H}\right)\left(w_{H}+I W B\right)+u_{H} B-c(\breve{a}),
$$

where we now need to use indexes to indicate sector. ${ }^{24}$ Using the fact that the equilibrium wage is determined independent of the $I W B$ by (34) and that (33) determines the unemployment rate, we have $\frac{d \breve{a}}{d I W B}=0$. There is thus no affect of an $I W B$ on the schooling cutoff in the base case when there are union firm wage bargains.

Based on the same assumptions as in the matching model about the valuation of leisure for workers not participating in the labor force, the marginal valuation is given by:

$$
\begin{aligned}
& \hat{l}=\left(1-u_{L}\right)\left(w_{L}+I W B\right)+u_{L} B \text { if } a<\breve{a} \\
& \hat{l}=\left(1-u_{H}\right)\left(w_{H}+I W B\right)+u_{H} B-c(a) \text { if } a \geq \breve{a}
\end{aligned}
$$

where $\frac{d \hat{l}}{d I W B}>0$ for both low and high ability workers.

Analogous to the matching model we have:

$$
\begin{aligned}
L F P= & \breve{a}\left[\left(1-u_{L}\right)\left(w_{L}+I W B\right)+u_{L} B\right] \\
& +(1-\breve{a})\left[\left(1-u_{H}\right)\left(w_{H}+I W B\right)+u_{H} B\right]-\int_{\breve{a}}^{1} c(a) d a, \\
E d u= & (1-\breve{a})\left[\left(1-u_{H}\right)\left(w_{H}+I W B\right)+u_{H} B\right]-\int_{\breve{a}} c(a) d a, \\
E m p= & \left(1-u_{L}\right) \breve{a}\left[\left(1-u_{L}\right)\left(w_{L}+I W B\right)+u_{L} B\right] \\
& +\left(1-u_{H}\right)(1-\breve{a})\left[\left(1-u_{H}\right)\left(w_{H}+I W B\right)+u_{H} B\right] \\
& -\left(1-u_{H}\right) \int_{\breve{a}}^{1} c(a) d a,
\end{aligned}
$$

where comparative statics again reveal that an $I W B$ will increase labor force participation, the stock of workers with higher education, and employment. All these effects are triggered by the reduced wage demands following the policy, which shifts the wage setting curve and reduce the unemployment rates. The effect of $I W B$ on the stock of educated workers works solely by encouraging participation among high ability workers with a high value of leisure, as the schooling cutoff is unaffected by an $I W B$ in the union-firm wage bargaining case.

\footnotetext{
${ }^{24}$ As in the basic matching model, expected income must increase with education, in order to make it worthwhile for some workers to aquire eduction. The necessary and sufficient condition for this is that productivity, all else being equal, is larger in the high skilled sector than in the low skilled sector, i.e., $A_{H}>A_{L}$.
} 